\title{
Evapotranspiration measurements in a Mediterranean forest stand by means of ecophysiological and microclimatic techniques
}

\author{
R. Valentini, G.E. Scarascia-Mugnozza and M. Sabatti
}

Istituto Biologico Selvicolturale, Università della Tuscia, Via De Lellis 4, 01100 Viterbo, Italy

\section{Introduction}

In the Mediterranean region, dry summers are quite common and water availability is one of the most important factors determining forest growth and development. Furthermore, the lack of water for public use experienced in central and southern Italy during the summer period, makes the analysis of the water cycle in forest and its impact on watershed management important.

The techniques available today for determining water consumption by forest stands range from large scale hydrological balances to transpiration measurements of an individual leaf. Among these, the heat pulse velocity technique (hpv) for measuring sap fluxes seems to be simple and reliable (Marshall, 1958; Swanson, 1962; Granier, 1985), but different approaches have to be compared, in order to determine its degree of accuracy. In this paper we compare the energy balance/ Bowen ratio and the hpv technique for determining water consumption of an oak stand.

\section{Materials and Methods}

The forest stand is located in central Italy, consists mainly of oaks (Quercus cerris L.) and is managed as coppice with standard trees originated by gamic reproduction. The stand averages 2400 sprouts and 97 standards of 2 age classes per ha (corresponding to the double and single harvesting cycle, respectively). The leaf area index ( $L A I)$ of the whole stand is 4.5 (Scarascia-Mugnozza et al., 1989).

Energy balance measurements were carried out by means of an exchange mechanism carrying 2 ventilated ceramic wick psychrometers (Gay, 1971). Net radiation was measured with a net radiometer (Middleton Inc.). All the micrometeorological data were collected every 10 min by a data logger (HP3421a) connected to a microcomputer (HP71). Net radiation was assumed to be mainly dissipated by the latent and the sensible heat fluxes. In order to compare the 2 methods, evaporation from the soil was considered negligible.

Heat pulse velocity was measured with a device constituted by 2 temperature probes (0.5 $\mathrm{mm}$ diam. J-type thermocouples) inserted into the xylem and one heat source $(1 \mathrm{~mm}$ diam.) placed $2 \mathrm{~cm}$ from the downstream sensor and $1.6 \mathrm{~cm}$ from the upstream one. hpv data were collected every $10 \mathrm{~min}$ together with micrometeorological measurements. 


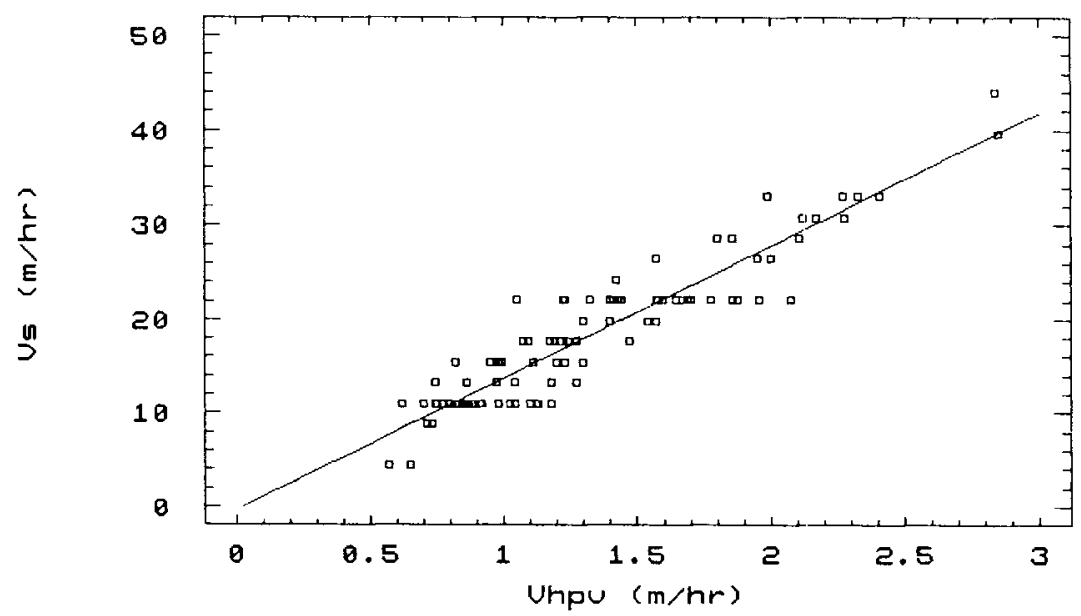

Fig. 1. Regression line of calibration. $V h p v=$ heat pulse velocity; $V s=$ real sap velocity.

The calibration procedure for the hpv system consisted of measuring in the field the water uptake of sampled trees, which represented the averages of the size classes. A plastic tank was attached around the stem and filled with water. The bark and the first xylem rings were cut in the water in order to allow water uptake. At the same time, hpv data were collected. The sapwood cross sectional area was determined by adding a blue dye to the water and counting with a microscope the number and area of vessels filled by the solution. The relationship between the real sap velocity $(V s)$ and the heat pulse velocity (VhpV) is presented in Fig. 1 . The fitted line has an $R^{2}$ regression coefficient of 0.88 .

\section{Results and Discussion}

The seasonal behavior of hpv and energy balance measurements together with the plant water status (predawn water potential) are presented in Fig. 2. After an initial increase due to a large evaporative demand at the beginning of July, transpiration measured by Bowen ratio and hpv techniques decreased continuously following the water stress evolution. At the beginning of the season, the predawn water potential was about $-0.5 \mathrm{MPa}$ for both sprouts and standards and it reached minimum values $(-2.6,-2.8 \mathrm{MPa}$ for sprouts and standards, respectively) during September.

Transpiration rates measured with the energy balance/Bowen ratio method ranged from 1.63 to $4.58 \mathrm{~mm} \cdot \mathrm{d}^{-1}$. At the beginning of the season, latent heat flux was $78 \%$ of net radiation corresponding to $2.91 \mathrm{~mm} \cdot \mathrm{d}^{-1}$, it reached a maximum in July $\left(4.58 \mathrm{~mm} \cdot \mathrm{d}^{-1}\right)$, while during the water stress periods it was a much smaller percentage $(37 \%)$, corresponding to $1.66 \mathrm{~mm} \cdot \mathrm{d}^{-1}$. These values are quite similar to those reported in another study on the hydrological balance of this forest for the years 1984--85 (Scarascia Mugnozza et al., 1988).

hpv measurements, integrated over the whole stand, paralleled the energy balance data: $3.42 \mathrm{~mm} \cdot \mathrm{d}^{-1}$ at the beginning of the season, $4.25 \mathrm{~mm} \cdot \mathrm{d}^{-1}$ in July and $1.63 \mathrm{~mm} \cdot \mathrm{d}^{-1}$ during the maximum water stress period. A calculated regression line between hpv and energy balance/Bowen 


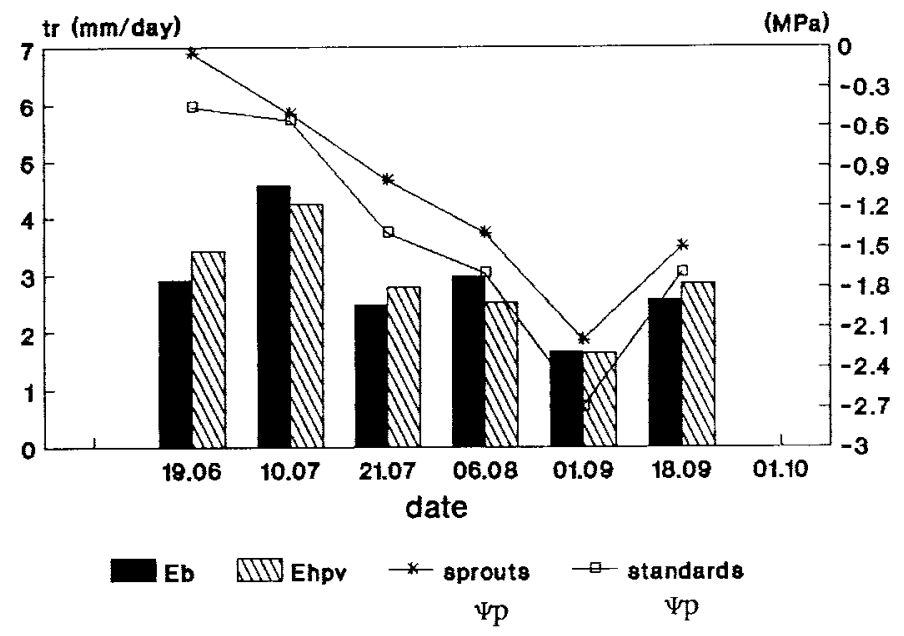

Fig. 2. Seasonal trend of daily transpiration rates estimated with the Bowen ratio/energy balance ( $E b$ ) and the heat pulse velocity (Ehpv) techniques. The seasonal trend of the predawn water potential $(\psi p)$, both for sprouts and standards, is also indicated.

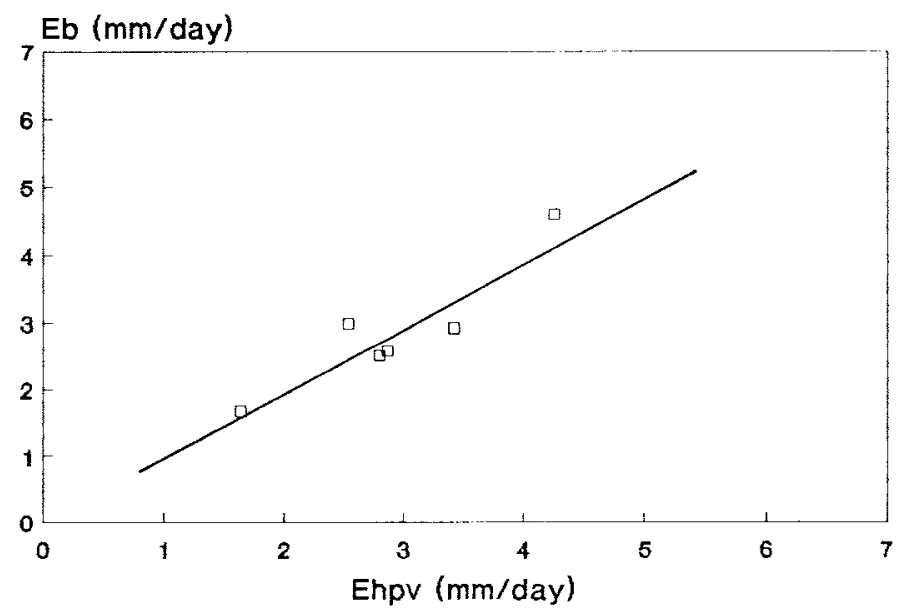

Fig. 3. Regression line between daily transpiration rates estimated with the Bowen ratio/energy balance (Eb) and heat pulse velocity (Ehpv) techniques.

ratio data shows a good correlation between the 2 techniques, presenting an $R^{2}$ coefficient of 0.84 (Fig. 3 ).

Transpiration rates of deciduous forests reported in the literature are somewhat higher than our data (Rauner, 1976) but these studies mainly relate to more humid climates, where transpiration rates are not limited by water stress and to forests with higher $L A I$. 


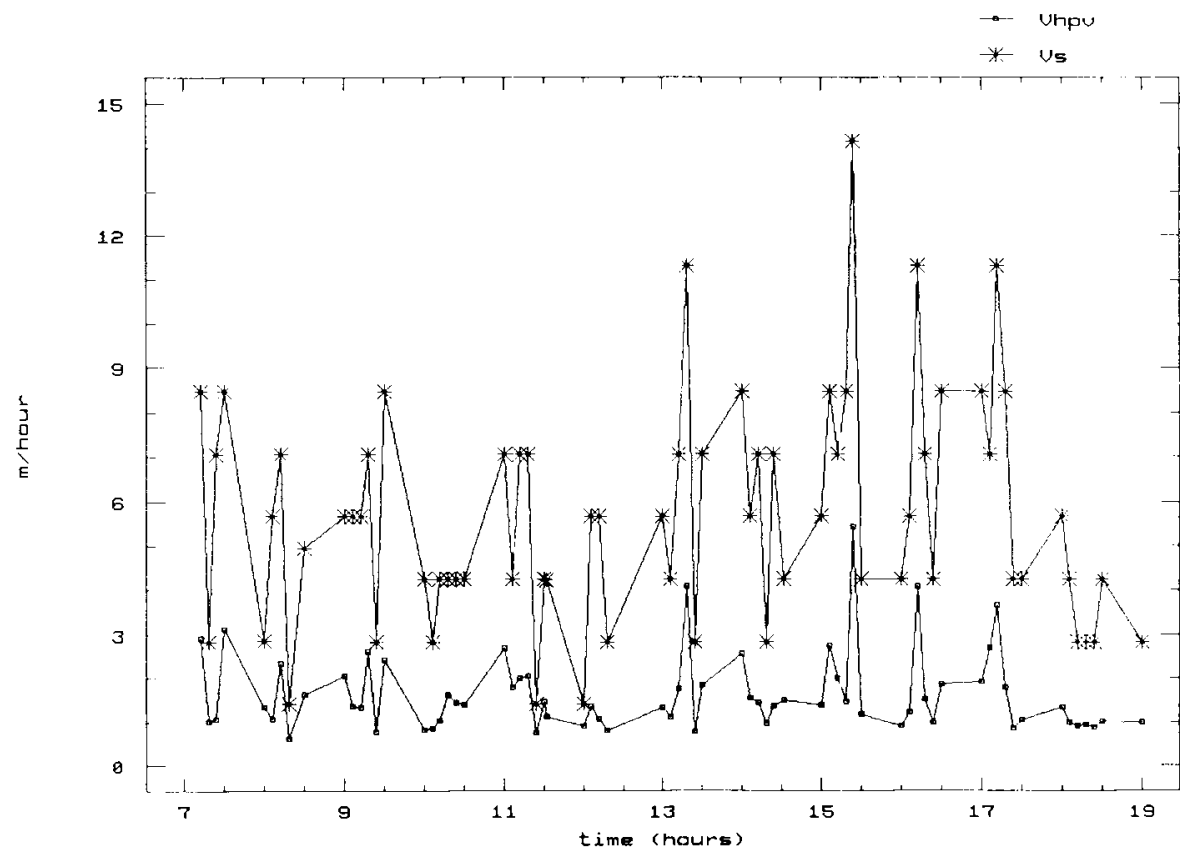

Fig. 4. Typical fluctuations of heat pulse velocity $(V h p v)$ and real sap velocity ( $V$ s) on a short time scale (10 $\mathrm{min})$.

hpv values ranged from 0 to $50 \mathrm{~m} \cdot \mathrm{h}^{-1}$. These values are rather high if compared with those of conifers (Lassoie et al., 1977), which were in the order of $0.2-1 \mathrm{~m} \cdot \mathrm{h}^{-1}$, but they are similar to the ones found in other ring-porous species (Miller et al., 1980).

A detailed analysis of hpv data taken every 10 min (Fig. 4) revealed several fluctuations throughout the day rather than a constant behavior. Since this particular pattern could be determined by experimental errors, the real sap velocity ( $V s)$, obtained with the calibration procedure, was compared with the heat pulse velocity ( $V h p v$ ). The coincidence of many of the peaks of the 2 fluctuating patterns shows that the technique is reliable and the observed irregular transpiration stream could be determined by other factors related to xylem cavitations, crown architec- ture and rapid variations of micrometeorological parameters.

This particular behavior, not evident in conifer trees, has also been shown by Miller et al. (1980), who observed fluctuations in sap velocities in $Q$. alba $L$. and $Q$. velutina Lam. of the same magnitude as those we have found in $Q$. cerris $L$.

\section{References}

Gay L.W. (1971) On the construction and use of ceramic wick thermocouple psychrometers. In: Psychrometry in Water Relations Research. (Brown W.R. \& Van Haveren B.P., eds.), Utah Agric. Exp. Stn., Logan, Utah, pp. 365

Granier A. (1985) Une nouvelle méthode pour la mesure du flux de sève brute dans le tronc des arbres. Ann. Sci. For. 42, 193-200

Lassoie J.P., Scott D.R.M. \& Fritschen L.J. (1977) Transpiration studies in Douglas fir using 
the heat pulse velocity technique. For. Sci. 23 , 377-390

Marshall D.C. (1958) Measurement of sap flow in conifers by heat transport. Plant Physiol. 33, 385-396

Miller R.D., Vavrina C.A. \& Christensen T.W. (1980) Measurement of sap flow and transpiration in ring-porous oaks using a heat pulse velocity technique. For. Sci. $26,485-494$

Rauner J.L. (1976) Decidous forest. In: Vegetation and the Atmosphere. (Monteith J.L., ed.), Academic Press, London, pp. 241-264
Scarascia Mugnozza G., Valentini R., Spinelli R. \& Giordano E. (1988) Osservazioni sul ciclo dell'acqua in un bosco di $Q$. cerris L. Ann. Accad. Ital. Sci. For. 37, 89-105

Scarascia-Mugnozza G., Valentini R., Giordano E. \& Del Lungo A. (1989) Modelling the coppice stand structure: an ecophysiological approach. Ann. Sci. For. 46 suppl., 519s-522s

Swanson R.H. (1962) An instrument for detecting sap movement in woody plants. U.S. Dept. Agric. For. Ser. Res. Pap. RM-68 